\title{
Aplicativo de apoio à doação de sangue: contribuições de especialistas sobre a funcionalidade da ferramenta
}

\author{
Blood donation support application: contributions \\ from experts on the tool's functionality
}

\author{
Joélia Rodrigues da Silva (https://orcid.org/0000-0001-6835-3724) ${ }^{1}$ \\ Christina César Praça Brasil (https://orcid.org/0000-0002-7741-5349) ${ }^{1}$ \\ José Eurico de Vasconcelos Filho (http://orcid.org/0000-0002-6881-0814) ${ }^{2}$ \\ Bruno Praça Brasil (https://orcid.org/0000-0003-0927-4692) ${ }^{3}$ \\ Larissa Barbosa Paiva (https://orcid.org/0000-0001-7942-1139) ${ }^{3}$ \\ Vinicius Freire de Oliveira (https://orcid.org/0000-0001-9011-5941) ${ }^{2}$ \\ Francisco Wandemberg Rodrigues dos Santos (https://orcid.org/0000-0002-2701-7617) ${ }^{3}$
}

${ }^{1}$ Programa de Pós-

Graduação em Saúde Coletiva, Universidade de Fortaleza (Unifor). Av. Washington Soares 1321, Edson Queiroz. 60811905 Fortaleza CE Brasil. joeliarodrigues@gmail.com ${ }^{2}$ Núcleo de Aplicação em Tecnologia da Informação Unifor. Fortaleza CE Brasil. ${ }^{3}$ Curso de Graduação em Medicina, Unifor. Fortaleza CE Brasil.

\begin{abstract}
Blood donation is a social practice that helps treat diseases and maintain public health. The DoeSangue application was designed and developed to support donor recruitment and loyalty, strengthening health promotion and social engagement. We aimed to assess the DoeSangue application from the perspective of hematology and hemotherapy experts. A methodological, applied and qualitative research was carried out from September 2015 to July 2017 in Fortaleza, Ceará. The study was based on Participatory Interaction Design associated with Symbolic Interactionism. After conducting the first two steps, application design and development in a laboratory and assessment by donor users, the application was validated by eight experts from the Fortaleza's public blood center. For data collection, the 'application validation form with experts' was used based on a Likert-type scale, and a focus group was conducted. The tool was positively assessed by participants, with an average Content Validation Index of 0.88. Evaluators pointed out, among other features, the tool's ability to promote interactivity, mobilization and social engagement, in addition to contributing to gathering and loyalty of blood donors.
\end{abstract}

Key words Blood donos, Technology, Health promotion, Qualitative research
Resumo A doação de sangue é uma prática social que auxilia no tratamento de doenças e na manutenção da saúde coletiva. O aplicativo DoeSangue foi concebido e desenvolvido para apoiar a captação e a fidelização de doadores, fortalecendo a promoção da saúde e o engajamento social. Objetivou-se avaliar o aplicativo DoeSangue sob a perspectiva de especialistas das áreas de hematologia e hemoterapia. Realizou-se uma pesquisa metodológica, aplicada e qualitativa, de setembro de 2015 a julho de 2017, em Fortaleza, Ceará. O estudo fundamentou-se no Design de Interação Participativo associado ao Interacionismo Simbólico. Após as duas primeiras etapas - concepção $e$ desenvolvimento do aplicativo em laboratório, $e$ avaliação pelos usuários doadores - o aplicativo foi validado por oito especialistas do hemocentro público de Fortaleza. Para a coleta de dados, utilizou-se o 'formulário de validação do aplicativo com especialistas', com base na escala de Likert, $e$ realizou-se um grupo focal. A ferramenta foi avaliada positivamente pelos participantes, com Índice de Validação de Conteúdo médio de 0,88. Os avaliadores apontaram, dentre outras funcionalidades, a capacidade da ferramenta em promover interatividade, mobilização e engajamento social, além de contribuir com a captação e a fidelização de doadores de sangue.

Palavras-chave Doadores de sangue, Tecnologia, Promoção da saúde, Pesquisa qualitativa 


\section{Introdução}

A doação de sangue salva milhões de vidas todos os anos. Pode auxiliar pacientes em tratamentos oncológicos, recém-nascidos prematuros, gestantes em situação de alto risco, pacientes hematológicos que necessitam da terapêutica transfusional, acidentados e com doenças potencialmente fatais, além de apoiar procedimentos médicos e cirúrgicos complexos.

Dentro do princípio da equidade, a doação de sangue representa um grande movimento social de trocas solidárias e de manutenção da vida por meio de ações voluntárias, altruístas e livres de preconceitos. $\mathrm{O}$ acesso à terapia sanguínea e aos hemoderivados - produtos sanguíneos - corresponde a uma das estratégias voltadas à equidade da assistência à saúde da população, sendo um componente essencial dos sistemas de saúde eficazes $^{1}$.

Em muitos países, a demanda por sangue e hemoderivados excede a oferta e os serviços enfrentam o desafio de disponibilizá-los de forma suficiente, além de garantir sua qualidade e segurança ${ }^{2}$. A oferta adequada só pode ser assegurada por meio de doações regulares voluntárias e não remuneradas. Nesse contexto, os avanços tecnológicos na saúde, a partir da introdução e da expansão das tecnologias $e$ Health, têm contribuído substancialmente com a acessibilidade às informações e aos serviços, fortalecendo o sistema de saúde e o atendimento dos pré-requisitos da equidade e da justiça social. O que também se aplica às iniciativas voltadas à captação e à manutenção de doadores de sangue.

A assistência hemoterápica brasileira conta com uma rede de hemocentros, com sede em todos os estados e no distrito federal, compreendendo 32 hemocentros coordenadores e 2.066 serviços de hemoterapia no Sistema Único de Saúde - SUS ${ }^{3}$. Segundo o Ministério da Saúde ${ }^{3}$, apenas $1,6 \%$ da população brasileira doa sangue. O percentual de doadores no país atende aos parâmetros da Organização Mundial de Saúde (OMS), que estipula a margem de $1 \%$ a $3 \%$ de doadores de sangue. Em 2018, 3,3 milhões de pessoas doaram sangue no Brasil, sendo $60 \%$ deste público formado por homens. Nesse mesmo ano, 2,8 milhões de pessoas precisaram receber transfusão sanguínea no país ${ }^{4}$.

A doação de sangue é uma estratégia social para a manutenção da saúde pública e deve ser exercida de forma voluntária, altruísta e anôni- ma, conforme orienta a legislação brasileira e a Organização Mundial de Saúde ${ }^{5}$. É também a concretização da integração social nas ações de saúde coletiva, de forma consciente e efetiva. Um estoque de sangue condizente com as necessidades populacionais ajuda a reduzir a mortalidade e as complicações clínicas.

Os serviços de hemoterapia buscam exaustivamente novas estratégias de marketing e de comunicação em saúde que possibilitem a manutenção do estoque de sangue, garantindo o atendimento satisfatório à população, gerando segurança às unidades de saúde e ajudando na recuperação dos pacientes. Assim, acredita-se que a utilização das tecnologias móveis na saúde (mHealth) pode ampliar a capilaridade na população, no que diz respeito à doação de sangue, favorecendo a captação e a fidelização de doadores. Ademais, as tecnologias $m$ Health atendem a diversos desejos e necessidades dos usuários, gerando adesão ao autocuidado com a saúde, envolvimento social em assuntos humanitários de apoio a pacientes, busca pelo bem-estar e qualidade de vida ${ }^{6}$.

Visando atender às necessidades do Hemocentro público do Estado do Ceará, o aplicativo DoeSangue foi concebido e desenvolvido na Universidade de Fortaleza (UNIFOR), no município de Fortaleza, Ceará, por uma equipe multidisciplinar, em uma parceria entre o Programa de Pós-Graduação em Saúde Coletiva e o Laboratório de Inovação do Núcleo de Aplicação em Tecnologia da Informação (NATI/UNIFOR).

A ferramenta conta com funcionalidades $\mathrm{e}$ características que visam preencher a lacuna de comunicação entre o hemocentro e o doador e/ ou cidadão. $\mathrm{O}$ aplicativo foi devidamente testado por doadores que participaram do teste de usabilidade, os quais o avaliaram de forma positiva e deram sugestões para a melhoria de algumas funcionalidades, como: dar mais celeridade ao agendamento da doação de sangue pelo aplicativo; melhorar a visualização do cursor em algumas telas do aplicativo e consertar a falha no sistema que provocava a saída do aplicativo quando selecionado o recurso 'Voltar'. Em seguida, foram feitos ajustes na ferramenta, o que justifica a necessidade de nova testagem e avaliação do aplicativo por especialistas.

Diante do exposto, o presente estudo tem como objetivo avaliar o aplicativo DoeSangue sob a perspectiva de especialistas das áreas de hematologia e hemoterapia. 


\section{Método}

Realizou-se uma pesquisa metodológica, de natureza aplicada e abordagem qualitativa, a qual fundamentou-se no método de criação do Design de Interação $(\mathrm{DI})^{7}$, respaldada pelo Interacionismo Simbólico ${ }^{8}$.

O Design de Interação ${ }^{7}$ favorece a utilização de recursos tecnológicos, pervasivos e interativos, constituindo um campo de estudo multidisciplinar. Este método subsidiou as questões norteadoras para a concepção, o desenvolvimento e a validação do aplicativo dentro do princípio da melhoria contínua. O Interacionismo Simbóli$\mathrm{Co}^{8}$, por sua vez, respaldou a interpretação dos significados atribuídos às interfaces do aplicativo nos testes realizados e possibilitou a compreensão dos sentidos, ações e interpretações dos especialistas durante o teste de validação da ferramenta e no grupo focal.

Diante do objetivo proposto neste estudo, sentiu-se a necessidade de unir as duas áreas do conhecimento para um maior aprofundamento na linguagem tecnológica, na análise dos sentidos e significados, no aperfeiçoamento interativo da ferramenta, valorizando a ótica dos especialistas e a comunicação ideal, visando à performance adequada para o acesso às informações.

Metodologicamente, Rogers et al. ${ }^{7}$ definem quatro fases para a construção do Design Interativo (DI) centrado no usuário, com base em um processo iterativo: levantamento de requisitos e identificação das necessidades dos usuários; design de alternativas e (re) design; construção do protótipo; e avaliação. Esse processo é caracterizado como iterativo, devido à impossibilidade de o produto emergir pronto para uso de uma só vez, necessitando de idas, vindas, trocas de experiências, avaliações e testes para que o ciclo se complete e permita melhoramentos contínuos $^{7,9}$. Essas fases são complementares e podem ser acessadas várias vezes até que se consiga atingir a excelência do produto.

A pesquisa foi desenvolvida em três etapas. A primeira ocorreu de setembro de 2015 a julho de 2016, quando se realizou a revisão de literatura, a concepção e o desenvolvimento do aplicativo no Laboratório de Inovação do Núcleo de Aplicação em Tecnologia da Informação (NATI) da UNIFOR. Adotou-se a técnica de benchmarking ${ }^{10}$ para o rastreio, nas lojas de aplicativos Google Play (Android) e AppStore (iOS), de tecnologias com teor semelhante e diretamente relacionadas à doação de sangue. A partir dessa ação, identificaram-se 24 aplicativos, nos idiomas Inglês e Português, sendo que somente 14 aplicativos possuíam relação direta com o produto e a tecnologia requeridos.

Ao final do processo de levantamento de requisitos funcionais nos 14 aplicativos selecionados, identificaram-se 10 relacionados às necessidades dos usuários e do hemocentro participante deste estudo. Outros seis requisitos $(6,8,9,11$, 14 e 16) não foram identificados nos aplicativos existentes, tendo sido propostos e desenvolvidos pelos pesquisadores deste estudo, como mostra o Quadro 1.

Foram propostos seis requisitos (37\%), dentre os 16 constantes no Quadro 1, como recursos inovadores $(6,8,9,11,14$ e 16). Esses requisitos relacionam-se às estratégias de captação, interação e fidelização dos doadores, configurando como diferenciais do DoeSangue.

Nesta etapa, foram contemplados os três primeiros passos dos processos interativos do ciclo de vida do Design de Interação Centrado no Usuário ${ }^{7}$ levantamento de requisitos e identificação das necessidades dos usuários; design de alternativas e (re) design; e construção do protótipo.

A segunda etapa da pesquisa (novembro de 2016) compreendeu o teste de usabilidade, com a avaliação da performance da ferramenta e da interação dos doadores de sangue com a tecnologia. Participaram do teste 11 doadores voluntários, com idades de 18 a 69 anos. O teste foi realizado no NATI/UNIFOR, sem interferências externas e com registro em vídeo, tendo sido aplicado um Formulário de Avaliação de Desempenho do Usuário para acompanhar e medir o desempenho dos participantes, calculando o tempo de duração em cada tarefa, as dificuldades encontradas, possíveis dúvidas, desenvoltura na navegação das telas, eficiência e satisfação dos presentes. Ao final, os participantes preencheram o Questionário Pós-Teste de Usabilidade - Doador, que possibilitou analisar a Interação Humano-Computador (IHC) e identificar a eficácia do DI e o desempenho do aplicativo.

A terceira etapa, objeto do presente artigo, ocorreu em julho de 2017, quando ocorreu a validação do aplicativo por especialistas. A ferramenta foi submetida a uma avaliação funcional e de conteúdo por oito profissionais da área de hematologia e hemoterapia, visando garantir a coerência das informações, o alinhamento com o público-alvo e a eficácia. $\mathrm{O}$ teste foi aplicado em ambiente controlado, silencioso e sem distrações (Laboratório de Inovação Tecnológica do NATI $)^{11}$, com duração aproximada de duas horas e meia. 
Quadro 1. Requisitos para o aplicativo DoeSangue, Fortaleza, Ceará, 2016.

\begin{tabular}{|c|c|}
\hline 1. Cadastrar o doador; & $\begin{array}{l}\text { 9. Permitir postagens de vídeos de sensibilização e de } \\
\text { depoimentos no aplicativo }\left(^{*}\right) \text {; }\end{array}$ \\
\hline 2. Agendar a doação de sangue; & $\begin{array}{l}\text { 10. Prover informações sobre o hemocentro } \\
\text { (localização, contatos, horário de funcionamento); }\end{array}$ \\
\hline $\begin{array}{l}\text { 3. Identificar inaptidão para doação de sangue e } \\
\text { informar o término da inaptidão para o doador; }\end{array}$ & $\begin{array}{l}\text { 11. Permitir cadastro nos Programas de } \\
\text { Relacionamento do hemocentro }\left(^{*}\right) \text {; }\end{array}$ \\
\hline $\begin{array}{l}\text { 4. Calcular e lembrar a data da próxima doação de } \\
\text { sangue; }\end{array}$ & $\begin{array}{l}\text { 12. Adotar recursos de gamificação no aplicativo - } \\
\text { pontos, badges (símbolos), entre outros - e design } \\
\text { persuasivo; }\end{array}$ \\
\hline $\begin{array}{l}\text { 5. Apresentar o local de coleta mais próximo do } \\
\text { doador; }\end{array}$ & 13. Oferecer recursos de notificação; \\
\hline $\begin{array}{l}\text { 6. Realizar convite para doação de sangue, por tipo } \\
\text { sanguíneo, por localidade e em situações de fenótipos } \\
\text { raros }\left(^{*}\right) \text {; }\end{array}$ & $\begin{array}{l}\text { 14. Disponibilizar laudos de resultados de exames } \\
\text { sorológicos (resultados negativos) pós doação }\left(^{*}\right) \text {; }\end{array}$ \\
\hline $\begin{array}{l}\text { 7. Possibilitar ao doador enviar convite aos amigos } \\
\text { para serem doadores; }\end{array}$ & $\begin{array}{l}\text { 15. Oferecer informações sobre doação automatizada, } \\
\text { doações especiais (autólogo) e esclarecimento sobre } \\
\text { mitos e dúvidas frequentes; }\end{array}$ \\
\hline $\begin{array}{l}\text { 8. Prover comunicação contínua com o cidadão no } \\
\text { aspecto da responsabilidade social, campanhas e } \\
\text { eventos, por meio de mensagens curtas }\left(^{*}\right) \text {; }\end{array}$ & $\begin{array}{l}\text { 16. Integrar o aplicativo ao banco de dados do } \\
\left.\text { hemocentro }{ }^{*}\right) \text {. }\end{array}$ \\
\hline
\end{tabular}

Em observância às orientações sugeridas por Rogers et al. ${ }^{7}$, a pesquisa cumpriu o seguinte percurso: apresentação breve sobre o estudo; gravação em vídeo do teste para assegurar o registro das expressões e ações dos participantes; assinatura do Termo de Consentimento Livre e Esclarecido; e preenchimento do Formulário de Validação do Aplicativo pelos Especialistas.

O Formulário de Validação do Aplicativo com Especialistas foi baseado na Escala de Likert $^{12}$, uma ferramenta bastante utilizada na sociologia, na psicologia e na administração para medir atitudes e comportamentos, dividido em três blocos de avaliação: Bloco 1 - objetivos do aplicativo (9 itens de avaliação); Bloco 2 - estrutura e apresentação da ferramenta (15 itens de avaliação); e Bloco 3 - relevância da tecnologia (5 itens de avaliação). Neste estudo, os itens da escala de Likert estavam graduados de 1 a 4 , sendo a pontuação 1 atribuída à pior avaliação e 4 à melhor, tendo sido o cálculo realizado com base no Índice de Validação de Conteúdo (IVC).

O IVC identifica a quantidade de itens da Escala de Likert que receberam pontuação ' 3 ' e ' 4 ' dentro do universo total de respostas. A pontuação 3 significa que a ferramenta está adequada e a nota 4 , totalmente adequada ${ }^{12}$. A partir das res- postas dos participantes, o cálculo do IVC é feito com base na seguinte fórmula: IVC = número de respostas ' 3 ' ou ' 4 ' dividido pelo número total de respostas.

Os valores finais do IVC variam de 0 a 1 ; onde valores iguais ou acima de 0,79 atestam a validade da tecnologia ${ }^{13}$. Valores abaixo de 0,79 denotam a necessidade de ajustes na ferramenta, no bloco ou item que recebeu essa pontuação.

Logo após o teste de validação, os especialistas sentiram a necessidade de se expressar e aprofundar um pouco mais as reflexões sobre a ferramenta, dada a relevância da tecnologia para o processo de captação de doadores. Por esse motivo, realizou-se um grupo focal $(\mathrm{GF})^{14}$ cinco dias após o teste de validação.

O grupo focal aconteceu na sede do hemocentro, em Fortaleza, Ceará, no mês de julho de 2017, e contou com a participação de sete dos oito especialistas que compuseram o teste de validação. Essa técnica de coleta de dados é bastante utilizada em pesquisas qualitativas, sendo apropriada para a captação de percepções e opiniões sobre uma situação ou um produto de interesse comum ao grupo ${ }^{14}$. Nas pesquisas em saúde, os GF são capazes de aglutinar várias áreas do conhecimento na interpretação dos dados e propi- 
ciam a interação grupal, sem deixar de considerar a intervenção individual no coletivo.

O grupo focal foi conduzido por uma moderadora e três observadores, tendo sido gravado em vídeo e em áudio para a garantia do registro das informações. Todos os participantes contribuíram com opiniões e relatos aprofundados sobre o assunto, tendo sido o debate guiado por um roteiro denominado 'Questões Norteadoras para o Grupo Focal', que versava sobre: contribuições do aplicativo para a prática de doação de sangue; a importância da ferramenta para incrementar a captação de doadores; percepções dos especialistas sobre a linguagem, a estrutura, o conteúdo e os recursos de bonificação; entre outros aspectos.

Os dados qualitativos obtidos na terceira etapa, assim como o registro em vídeo do teste de validação e do grupo focal, foram analisados com base no método de Análise de Conteúdo na modalidade temática ${ }^{15}$, perpassando pela pré-análise, exploração do material, tratamento dos resultados e interpretação ${ }^{16}$.

Os dados obtidos a partir do teste de validação e do grupo focal realizados com os especialistas resultaram na organização do conteúdo em duas temáticas, quais sejam: alcance dos objetivos, estrutura e funcionalidade do aplicativo na visão dos especialistas; e relevância do aplicativo - o que dizem os especialistas.

Em seguida, o tratamento e a interpretação dos resultados possibilitou elaborar uma síntese dos achados, o estabelecimento de um diálogo entre as temáticas identificadas, o objetivo, os pressupostos do estudo e o alinhamento com a literatura. Nesse contexto, realizaram-se inferências e interpretações sobre as percepções dos especialistas acerca do aplicativo DoeSangue.

Para preservar as identidades dos participantes, utilizou-se a letra " $E$ " seguida de números de 1 a 7 . Dessa forma, E1 representa especialista 1 e assim sucessivamente.

Os resultados desta pesquisa vêm sendo reconhecidos no meio científico ${ }^{17}$. Vale ressaltar que os procedimentos ético-legais da pesquisa seguiram as normas previstas na Resolução no 466, de 12 de dezembro de 2012, do Conselho Nacional de Saúde $(\mathrm{CNS})^{18}$. Destaca-se que a pesquisa obteve aprovação pelo Comitê de Ética da UNIFOR.

\section{Resultados e discussão}

Participaram da validação do aplicativo DoeSangue 4 médicos(as), 2 enfermeiras, 1 assistente social e 1 terapeuta ocupacional. Os especialistas atuam, especificamente, no processo de captação e fidelização de doadores de sangue (3), no processamento do sangue (1), na medicina transfusional (2), na rastreabilidade e vigilância do processo transfusional (1) e na direção geral do hemocentro (1). Estes foram captados no hemocentro público de acordo com o grau de conhecimento técnico, tempo de experiência na área, interesse e disponibilidade em colaborar com o estudo.

Nielsen e Mack $^{19}$ apontam que o número de participantes em testes de validação deve ser de, no mínimo três e, no máximo, cinco. Ressalta-se, entretanto, que não há uma parametrização ou consenso desse quantitativo na literatura. Cockton e Woolrych ${ }^{20}$ argumentam que o número de especialistas nesse teste depende do tipo de problema e da complexidade do artefato. Assim, a inclusão de oito especialistas no teste em questão alinha-se ao que preconizam Dumas e Redish ${ }^{21}$.

As temáticas apresentadas a seguir - alcance dos objetivos, estrutura e funcionalidade do aplicativo na visão dos especialistas; e relevância do aplicativo: o que dizem os especialistas - refletem as contribuições do aplicativo para a funcionalidade da ferramenta.

\section{Alcance dos objetivos, estrutura e funcionalidade do aplicativo na visão dos especialistas}

O trabalho desenvolvido culminou com a inclusão, no aplicativo, das doze interfaces apresentadas na Figura 1, cujas funcionalidades foram avaliadas por especialistas.

Após responderem às questões propostas no formulário de validação do aplicativo com base na Escala de Likert, os especialistas pontuaram e fizeram observações e sugestões relevantes para a análise qualitativa, cujos resultados estão dispostos a seguir.

O Bloco 1 - Objetivos (Tabela 1) obteve IVC médio de 0,88 . Este resultado mostra que o DoeSangue é capaz de alcançar seus propósitos, metas ou fins, a partir da sua utilização. Entretanto, os itens 1 e 2 foram classificados como abaixo do IVC aceitável, 0,63 e 0,75, respectivamente; o que indica a necessidade de adequação da linguagem utilizada no aplicativo para uma maior aproximação ao público-alvo (doadores e potenciais doadores). Consideram, com a avaliação do item 2, a necessidade de tornar as informações melhor dimensionadas para a orientação no processo de doação de sangue, como também para o esclarecimento de dúvidas do público-alvo. Esses 


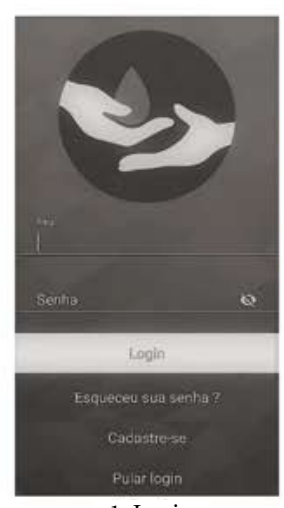

1. Login

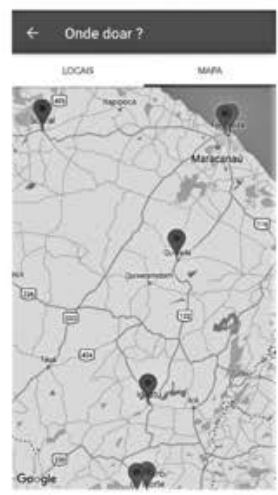

5. Onde doar

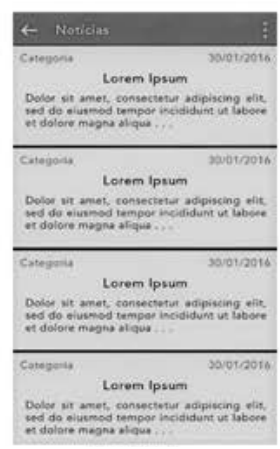

9. Notícias

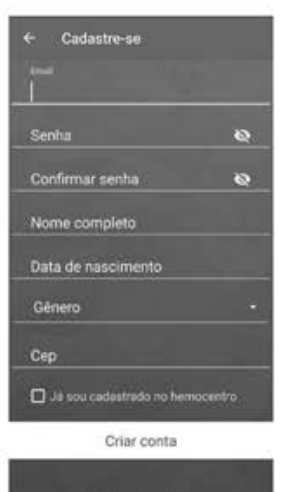

2. Cadastro

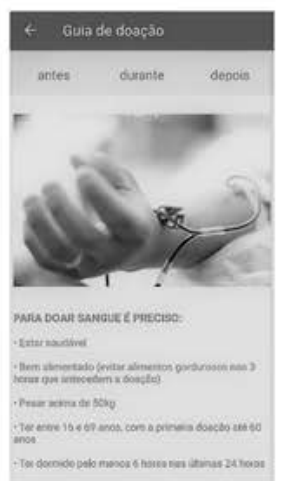

6. Guia de doação

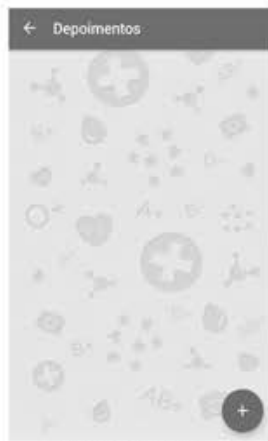

10. Depoimentos

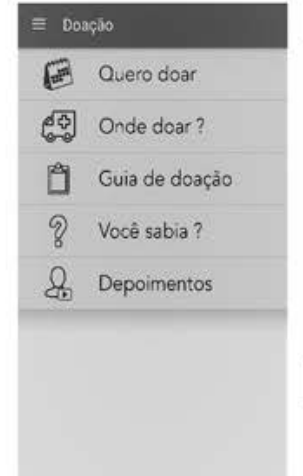

3. Menu principal

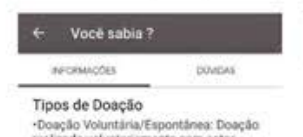

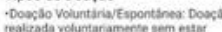

Situaçles que podem impedir a

doaçรี้

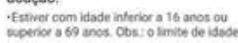

Situaç̧es que impedem a doaçăo Situacoes que impede
definitivamente:

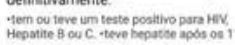

Situaç̄es que impedem a doaçăo temporariamente:

- Por 48 horas : se roceder vosing

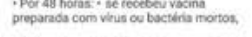

7. Você sabia? (Informações)

\section{$\equiv$ Historico}

Vidas salvas

Número de doaçós

Üitima doạçáo

Número de compartihamentos

Indonsificador PF 0031102016999

Mambro desce

Conquistos

DOQ1

11. Histórico do doador
4. Agendamento

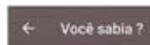

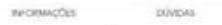

Eseguro doar sangue?

A doachlo nlo traz dano ao doocos

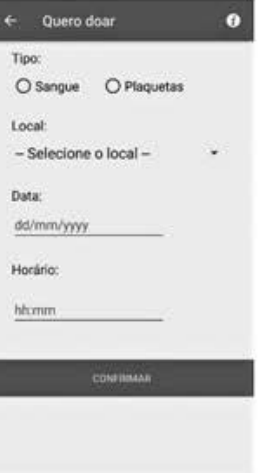

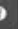

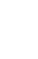

Alcheta ferta por peofiesionion

Quanto tempo dura a doaç̧o de

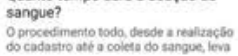
As pessoas que tern tatuagem podem doar?

As pessous que possuen tatuagen e

Epreciso apresentar algum Epreciso apresentar algum de sangue?

8. Você sabia? (Dúvidas)

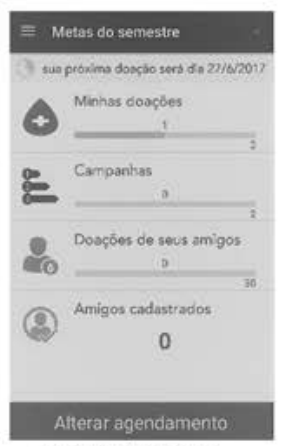

12. Metas do doador

Figura 1. Ilustração do aplicativo DoeSangue.

Fonte: NATI/UNIFOR (2016).

aspectos merecem atenção e dizem respeito ao conteúdo do aplicativo e sua objetividade, o que direciona a futuros ajustes na ferramenta, atendendo ao princípio da iteratividade do Design de Interação Participativo Centrado no Usuário ${ }^{7}$.

Os especialistas apontaram que as informações sobre restrições e impedimentos temporários e/ou definitivos para realizar uma doação de sangue deve ser de domínio do profissional do hemocentro que realiza a triagem clínica. Assim, sugeriram retirá-la do conteúdo do aplicativo. Esse argumento dos avaliadores está fundamentado na Portaria Ministerial no 158/2016, que orienta o processo de triagem na doação de sangue, etapa de extrema importância que visa minimizar os riscos de contaminação do paciente por meio da transfusão sanguínea ${ }^{22}$. Os especialistas defendem que a população interessada em doar 
Tabela 1. Índice de Validação de Conteúdo (IVC) quanto à análise dos objetivos do aplicativo DoeSangue.

\begin{tabular}{|c|c|}
\hline Objetivos & IVC \\
\hline $\begin{array}{l}\text { 1. A linguagem utilizada no aplicativo está compatível com o público-alvo (doadores e } \\
\text { potenciais doadores). }\end{array}$ & 0,63 \\
\hline $\begin{array}{l}\text { 2. As informações estão adequadas para a orientação no processo de doação de sangue, } \\
\text { como também, o esclarecimento de dúvidas do público-alvo. }\end{array}$ & 0,75 \\
\hline $\begin{array}{l}\text { 3. As estratégias propostas no aplicativo para a doação de sangue pelo usuário } \\
\text { apresentam consistência e efetividade neste processo. }\end{array}$ & 0,88 \\
\hline $\begin{array}{l}\text { 4. A estratégia proposta de acesso às informações personalizadas do doador por meio do } \\
\text { aplicativo - como data da última doação, tipo sanguíneo, número de doações realizadas, } \\
\text { acesso ao resultado de exames, entre outros - se apresentam como estratégia válida. }\end{array}$ & 0,88 \\
\hline $\begin{array}{l}\text { 5. Os recursos oferecidos pelo aplicativo podem gerar compromisso do público-alvo } \\
\text { com a manutenção do estoque de sangue do hemocentro. }\end{array}$ & 0,88 \\
\hline $\begin{array}{l}\text { 6. O conteúdo é interessante e pode gerar interesse para que o usuário mantenha o } \\
\text { aplicativo instalado no celular. }\end{array}$ & 0,88 \\
\hline $\begin{array}{l}\text { 7. O recurso de bonificação pode gerar engajamento dos usuários com a temática da } \\
\text { doação de sangue. }\end{array}$ & 1,0 \\
\hline $\begin{array}{l}\text { 8. O recurso de bonificação pode apoiar os hemocentros na divulgação de campanhas e } \\
\text { disseminação de notícias relevantes ao público-alvo. }\end{array}$ & 1,0 \\
\hline $\begin{array}{l}\text { 9. O aplicativo pode gerar interesse nos hemocentros para utilizar como ferramenta de } \\
\text { captação de doadores de sangue. }\end{array}$ & 1,0 \\
\hline Média do IVC & 0,88 \\
\hline
\end{tabular}

Fonte: Autoria própria (2017).

precisa estar orientada sobre o processo da doação de sangue, como expressa E1:

...ao colocar o critério diretamente [no aplicativo], se pode e se não pode [doar], você começa a dar uma informação que o doador tanto pode manipular como você pode desatualizar [o aplicativo]... A preocupação está na eficácia da informação, tanto para a população, quanto para o hemocentro... Tem gente que aprende [a informação] $e$ responde... manipulando. (E1)

Além dos cuidados com a segurança transfusional, os participantes destacaram que a informação em excesso pode desestimular a ida do candidato ao hemocentro, uma vez que terá acesso às causas de inaptidão antes de se candidatar à doação. Pontuaram que o interessante é

...não barrar que ele venha ao serviço de saúde... Na triagem, é que ele vai saber se pode ou não [doar]... assim, buscar o serviço de saúde, buscar o hemocentro, já faz com que a gente trabalhe esse doador... (E4).

Esse fato viabiliza, inclusive, que a equipe do hemocentro possa orientar o doador a buscar outro serviço de saúde para algum acompanhamento que necessite.

Os recursos de bonificação ofertados pelo aplicativo a cada tarefa realizada pelo usuário alcançaram pontuação máxima (IVC 1,0), sendo esta reconhecida como uma estratégia de capta- ção de doadores de sangue com vasto poder de engajamento social, portanto, de interesse direto do hemocentro do Ceará e, possivelmente, dos demais hemocentros do país.

A bonificação é o ponto positivo máximo [do aplicativo], muito bom mesmo! [...] (E4); e

...ter a pontuação sua de doação, ter a pontuação dos seus amigos, você perceber que você está fazendo um bem independente da sua presença e lá tem outras pessoas fazendo o bem, é muito gratificante... Outra coisa boa é poder interagir com os amigos. (E8)

A gamificação, segundo Kapp ${ }^{23}$, caracterizase pelo alto poder de engajamento das pessoas por meio de recursos mecânicos, intuitivos e simbólicos que podem contribuir para o aprendizado, envolvimento e divulgação de informações, percorrendo o caminho da assimilação à ação, tornando-se parte de um movimento social não declarado, podendo ampliar esse caminho até o cume de fazer apologia a uma ideia, produto, serviço ou causa.

No tocante à estrutura e apresentação (Bloco 2), o aplicativo obteve IVC médio de 0,90 , mostrando que o nível de satisfação dos especialistas com a ferramenta foi elevado. Porém, os itens 1, 3 e 13 foram avaliados com IVC discretamente abaixo do satisfatório $(0,75)$, como mostra a Tabela 2. Estes itens referem-se à eficácia da infor- 
mação contida no aplicativo em relação ao público-alvo, seu alinhamento ao segmento social e, inclusive, se a formatação da fonte está propícia. Ressalta-se que a pontuação atribuída a esses itens está alinhada aos itens 1 e 2, do bloco 1 (objetivos), demonstrando coerência na avaliação.

Nesse contexto, é possível extrair dos relatos dos especialistas uma preocupação com a qualidade da informação que é disponibilizada pelo aplicativo, de forma que não desestimule a ida do doador ao hemocentro e, ao mesmo tempo, possa envolvê-lo no cenário da doação de sangue como uma prática inerente ao exercício da cidadania e de responsabilidade social, como aponta E1:

...eu sugiro que o conteúdo seja construído na visão do altruísmo e não na visão de quem pode e de quem não pode doar. Primeiro, porque quem pode e quem não pode, muda muito, isso vai exigir revisões, porque toda vida que a Portaria do Ministério mudar, aí, o aplicativo vai ficar um tempo desatualizado. (E1)

Os especialistas apontaram que o conteúdo do aplicativo segue uma sequência lógica, é atrativo e estimulante - itens 4 e 5 (Tabela 2), além de considerarem os ícones, as telas e as letras utilizadas na ferramenta totalmente adequadas itens 10, 11 e 14, com IVC 1,0. O item 15 remete à quantidade de informações constantes no aplicativo, também avaliado com IVC máximo $(1,0)$, em oposição ao item 2 do bloco 1 e a algumas falas do grupo focal, as quais versam sobre o mes- mo aspecto. Isso mostra certa inconsistência da avaliação. O que precisará de uma nova avaliação, após a realização dos ajustes que serão implementados como desdobramento deste estudo.

O Interacionismo Simbólico ${ }^{8}$ favorece compreender a dialética dos significados, em que as falas em divergência podem presumir a representação simbólica da vontade coletiva. Casagran$\mathrm{de}^{24}$ afirma "trata-se da dimensão normativa da comunidade social, que se estrutura na forma de um horizonte e que orienta as atitudes dos distintos indivíduos". Isso ocorre de tal forma, que o desejo em adequar a ferramenta às necessidades do hemocentro pode ter influenciado na avaliação do aplicativo.

Durante o grupo focal com os especialistas, várias sugestões emergiram e algumas dúvidas foram esclarecidas acerca da funcionalidade e do potencial tecnológico do aplicativo. No que se refere às dúvidas, funções como agendar uma doação, gravar um depoimento, gerar campanhas de mobilização social, gerar notícias, convidar doadores e amigos de doadores a comparecerem ao hemocentro, dependem da integração do aplicativo com o banco de dados do hemocentro; porém alguns participantes não haviam compreendido.

... eu fiz um agendamento errado, mas fiz de propósito. Eu agendei uma doação de plaqueta para o IJF e o aplicativo agendou, essa data é inválida, por exemplo, doar plaqueta no domingo no IJF eu não posso... (E4).

Tabela 2. IVC quanto à estrutura e apresentação do aplicativo DoeSangue.

\begin{tabular}{lr}
\hline \multicolumn{1}{c}{ Estrutura e Apresentação } & IVC \\
\hline 1. O aplicativo é apropriado para orientar o público-alvo quanto à doação de sangue e de plaquetas. & 0,75 \\
2. As informações apresentadas estão cientificamente corretas. & 0,88 \\
3. O conteúdo está adequado ao nível sociocultural do público-alvo. & 0,75 \\
4. Há uma sequência lógica do conteúdo proposto. & 1,0 \\
5. O conteúdo é atrativo e estimulante. & 1,0 \\
6. A linguagem é clara e objetiva. & 0,88 \\
7. As informações dirigidas à captação de doadores são suficientes e adequadas. & 0,88 \\
8. As ilustrações (imagens) são pertinentes ao conteúdo. & 0,88 \\
9. As ilustrações (imagens) são claras e de fácil compreensão. & 0,88 \\
10. As telas estão bem estruturadas e de fácil navegação. & 1,0 \\
11. Os ícones estão adequados e auxiliam o usuário a compreender e usar o aplicativo. & 1,0 \\
12. As cores aplicadas ao texto estão adequadas e facilitam a leitura do conteúdo. & 0,88 \\
13. O tamanho das letras dos títulos, subtítulos e texto estão adequados. & 0,75 \\
14. O tipo de letra utilizado facilita a leitura. & 1,0 \\
15. A quantidade de informações contidas no aplicativo são adequadas. & 1,0 \\
Média do IVC & 0,90 \\
\hline
\end{tabular}


No que se refere às dúvidas e sugestões, Minayo et al. ${ }^{15}$ afirmam que essa formatação de coleta de dados em grupo pode albergar uma função complementar ao estudo, uma vez que agrega ferramentas de pesquisa como brainstorming (chuva de ideias), despertando questões antes não mencionadas e expectativas antes ocultas ou não sentidas. Os desejos percebidos e as inferências captadas durante o Grupo Focal consolidam o pensamento iterativo do Design Participativo ${ }^{7}$, sugerindo o processo contínuo de melhoria a ser implementado durante a execução do ciclo de desenvolvimento tecnológico.

\section{Relevância do aplicativo: o que dizem os especialistas}

Os especialistas foram unânimes em afirmar a importância do aplicativo no cenário da doação de sangue. O bloco 3 alcançou o maior IVC médio do teste $(0,95)$, sendo respaldado por depoimentos, como:

... um aplicativo como esse é revolucionário diante da captação de doadores (E4).

Aldamiz-Echevarria e Aguirre-Garcia ${ }^{25}$ ressaltam a importância de o hemocentro adotar recursos de marketing para captar novos doadores de sangue e promover ações de fidelização. Para tanto, salienta o uso das redes sociais e das tecnologias digitais para estabelecer proximidade e relacionamento com o doador. O aplicativo está estruturado para ser conectado tanto ao banco de dados do hemocentro quanto às redes sociais do usuário, oferecendo possibilidade de divulgar as campanhas de doação de sangue e convidar os amigos a abraçar a causa, por meio dos recursos de gamificação.

Kotler et al. ${ }^{26}$ afirmam que identificar as reais necessidades do público-alvo, visando solucionar problemas, é o maior desafio de um negócio. $\mathrm{O}$ reconhecimento do potencial desta ferramenta sinaliza que o objetivo geral deste trabalho de conceber uma tecnologia mHealth para ampliar a captação e a fidelização de doadores de sangue, apoiando a promoção da saúde, foi atingido.

...de uma certa forma isso vai realmente revolucionar o trabalho de captação de doadores... eu fiquei tão empolgada com a situação... alguns doadores fidelizados me conhecem, têm o meu contato, têm o meu e-mail... e, em conversas informais.. você pergunta, o que você acha se tivesse acesso às informações do hemocentro de forma mais fácil? Eles dizem: 'Ah seria ótimo!' E eles começam a falar realmente dessa necessidade. Então, foi isso que eu achei revolucionário. Parabéns! Muito bom... vai dar um reforço poderoso na captação de doadores, tanto para o doador, como para as pessoas que não podem doar, mas que gostariam... (E4)

Diante dos resultados verificados na Tabela 3 , os profissionais demonstram reconhecer que o aplicativo oferece novas estratégias que podem impulsionar a doação de sangue e favorecer a manutenção do estoque de sangue em níveis ideais, contribuindo, inclusive, com melhorias nos processos de trabalho do ciclo do sangue, otimizando custos e evitando desperdícios, conforme reforça: Acho que é de grande valia ele [o doador] saber que naquele momento ele pode doar e que ele está apto... vai ajudar demais... demais! (E6)

Ademais, vale ressaltar que é mais rentável investir na fidelização de doadores reais do que concentrar esforços na captação de possíveis doadores ${ }^{27}$. Ações de fidelização geram menor custo que ações de atração, tendo em vista que estas são direcionadas à grande massa ou aos segmentos sociais que podem ou não ter a intenção em doar sangue, o que demanda alto investimento publicitário. Por sua vez, presume-se que um doador real já compreende o processo de doação e encontra-se mais inclinado a repetir a ação.

O valor geral do IVC do aplicativo, contabilizando os três blocos de análise, foi de 0,91 , considerado como alto índice de concordância por parte dos especialistas, mostrando-se válido quanto a conteúdo, estrutura, funcionalidade e objetivo. Essa métrica ressalta a análise sobre determinados pontos do instrumento e de seus itens facilitando, assim, a compreensão e a avaliação da tecnologia ${ }^{28}$.

Salienta-se que as interfaces depoimentos (tela 8), notícias (tela 9) e mensagens (tela 10) presentes na Figura 1, não foram testadas pelo fato de suas funcionalidades dependerem diretamente da implantação do módulo administrativo do sistema, o que somente será feito após a integração do aplicativo com o banco de dados do hemocentro.

\section{Considerações finais}

No que se refere ao objetivo e à relevância do DoeSangue, os especialistas afirmaram a expressiva contribuição que o mesmo pode oferecer à causa da doação de sangue, que ultrapassa os muros de qualquer hemocentro e passa a ter significado coletivo, levando conhecimento e orientação à população com vistas à promoção da saúde como um recurso para a vida.

No que diz respeito à coleta de dados e sua interpretação, foi possível verificar os resultados positivos quanto à funcionalidade e a apresen- 
Tabela 3. IVC quanto à relevância do aplicativo DoeSangue.

\begin{tabular}{lr}
\hline \multicolumn{1}{c}{ Relevância } & IVC \\
\hline 1. O aplicativo estimula a prática da doação de sangue. & 1 \\
2. O material aborda os assuntos necessários, dentro do contexto da doação de sangue, para & 0,75 \\
quem Não É doador & 1 \\
3. O material aborda os assuntos necessários, dentro do contexto da doação de sangue, para & \\
quem É doador & 1 \\
4. O material está adequado para auxiliar os usuários no processo da doação de sangue. & 1 \\
5. O aplicativo é relevante para a promoção da saúde. & 0,95 \\
Média do IVC & \\
\hline
\end{tabular}

Fonte: Autoria própria (2017).

tação do aplicativo, pois, em geral, mostraram uma boa aceitação dos participantes, os quais demonstraram real interesse pela ferramenta, gerando significado social. As manifestações de alguns especialistas em ampliar as funcionalidades do aplicativo remetem ao potencial percebido a partir do uso da tecnologia. Os avaliadores reconhecem os recursos modernos da ferramenta (bonificações e integração com o banco de dados do hemocentro), os quais podem contribuir com uma mudança de cultura favorável à prática da doação de sangue, construindo um 'outro generalizado' mais consciente e envolvido com a causa. A possibilidade de personalizar o aplicativo com a linguagem do hemocentro pode gerar adesão dos demais hemocentros do país, o que, na visão dos especialistas, seria uma grande contribuição às causas relacionadas à captação e fidelização de doadores de sangue.

A adoção do método de pesquisa qualitativa, como o grupo focal e o índice de validação de conteúdo, amparado por teorias como o Design de Interação Participativo e o Interacionismo Simbólico, para a análise e a interpretação dos dados traz maior profundidade e conhecimento sobre as novas relações sociais impulsionadas pelo avanço das mídias digitais.
Acredita-se que este estudo contribui com a dinâmica da saúde coletiva, a partir do conceito de equidade, inerente aos princípios de promoção da saúde pública. Ademais, os hemocentros de todas as nações caminham para a adoção da doação de sangue $100 \%$ voluntária, movida por conceitos solidários e altruístas. Entende-se, portanto, que para o alcance desse ensejo é preciso investir em novas tecnologias, eficazes e pervasivas, que modifiquem o comportamento do usuário para a doação de sangue habitual em compromisso sincero com a manutenção do estoque de sangue de sua cidade, estado e país.

\section{Colaboradores}

JR Silva, CCP Brasil, JE Vasconcelos Filho, BP Brasil, LB Paiva, VF Oliveira e FWR Santos participaram de todas as etapas do estudo, perpassando pelo planejamento, revisão de literatura, coleta e análise de dados, escrita do artigo e revisão crítica do material. 


\section{Referências}

1. Brasil. Organização Pan-Americana da Saúde (OPAS). Dia Mundial do Doador de Sangue 2019 | Sangue seguro para todos (2019). [acessado 2019 Jun 9]. Disponível em: https://www.paho.org/ bra/index.php?option $=$ com_content $\& v i e w=$ article\&id $=5950$ : diadoadorsangue2019\&Itemid $=838$

2. Rodrigues RSM, Lino MM, Reybnitz KS. Estratégias de captação de doadores de sangue no Brasil: um processo educativo convencional ou liberador? Saúde Transf Social 2011;3(1):166-173.

3. Brasil. Ministério da Saúde (MS). Dezesseis a cada mil brasileiros doam sangue (2019). [acessado $2020 \mathrm{Abr} 9$ ]. Disponível em: https:/www.saude.gov.br/noticias/ agencia-saude/45520-dezesseis-a-cada-mil-brasileiros-fazem-doacao-de-sangue

4. Brasil. Agência Nacional de Vigilância Sanitária (Anvisa). $7^{\circ}$ Boletim de Produção Hemoterápica - Hemoprod 2018 (2020). [acessado 2020 Abr 9]. Disponível em: http://portal.anvisa.gov.br/ documents/4048533/4993603/7\%C2\%BA+Boletim + de + Produ $\%$ C3\%A7\% $3 \%$ A3o + Hemoter \%C3\%A1 pica/9ec3ceba-8e20-4aa6-8aa2-d5f953af$\mathrm{cf5c}$

5. Brasil. Agência Nacional de Vigilância Sanitária (Anvisa). Lei 10.205, de 21 de março de 2001. Regulamenta o $\$ 4^{\circ}$ do art. 199 da Constituição Federal, relativo à coleta, processamento, estocagem, distribuição $\mathrm{e}$ aplicação do sangue, seus componentes e derivados, estabelece o ordenamento institucional indispensável à execução adequada dessas atividades, e dá outras providências. Diário Oficial da União 2001; 21 mar.

6. Irvine $A B$, Russell $\mathrm{H}$, Manocchia M, Mino DE, Glassen TC, Morgan R, Gau JM, Birney AJ, Ary DV. Mobile-Web app to self-manage low back pain: randomized controlled trial. J Med Internet Res [periódico na Internet]. 2015 jan [acessado 2019 Jun 9]; 17(1): [cerca de 22 p.]. Disponível em: https://www.ncbi.nlm. nih.gov/pubmed/25565416

7. Rogers Y, Sharp H, Preece J. Design de interação: além da interação humano-computador. $3^{\mathrm{a}}$ ed. Porto Alegre: Bookman; 2013.

8. Blumer H. Symbolic Interactionis Perspective and Method. London: University of California Press, Ltd.; 1969.

9. Gould J D, Lewis CH. Designing for usability: key principles and what designers think. Communications of the ACM 1985; 28(3):300-311.

10. Ozcan YA. Health Care Benchmarking and Performance Evaluation: An Assessment using Data Envelopment Analysis (DEA). USA: Springer Science; 2014.

11. Barbosa SDJ, Silva BS. Interação humano-computador. Rio de Janeiro: Elsevier; 2011.

12. Wynd CA, Schmidt B, Schaefer MA. Two quantitative approaches for estimating content validity. West J Nurs Res 2003; 25(5):508-518.

13. Polit DF, Beck CT. The content validity index: are you sure you know what's beingre ported? Critique and recomendations. Reva Nurshealth 2006; 29(5):489497.

14. Trad LAB. Grupos focais: conceitos, procedimentos e reflexões baseadas em experiências com o uso da técnica em pesquisas de saúde. Physis 2009; 19(3):777796.
15. Minayo MCS, Deslandes SF, Gomes R. Pesquisa social: teoria, método e criatividade. 33a ed. Petrópolis: Vozes; 2013.

16. Bardin L. Análise de conteúdo. Lisboa: Edições 70; 2011.

17. Silva JR, Brasil CCP, Brasil BP, Paiva LB, Oliveira VF, Vasconcelos Filho JE, Santos FWR. Avaliação do aplicativo DoeSangue por especialistas. In: $7^{\circ}$ Congresso Ibero-Americano em Investigação Qualitativa. Investigação Qualitativa em Saúde - CIAIQ Atas 2018; 2: 1468-1477.

18. Brasil. Conselho Nacional de Saúde (CNS). Resolução $n^{\circ} 466$, de 12 de dezembro de 2012. Diretrizes e normas regulamentadoras de pesquisas envolvendo seres humanos. Diário Oficial da União 2012; $13 \mathrm{dez}$.

19. Nielsen J, Mack RL. Usability Inspection Methods. New York: John Wiley \& Sons Inc; 1994.

20. Cockton G, Woolrych A. Understanding inspection methods: lessons from an assesment of heuristic evaluation. Berlim: Springer-Verlag; 2001.

21. Dumas JS, Redish JC. A Practical Guide to Usability Testing. Bristol: Intellect; 1999.

22. Brasil. Ministério da Saúde (MS). Portaria no 158, de 4 de fevereiro de 2016. Redefine o regulamento técnico de procedimentos hemoterápicos. Diário Oficial da União 2016; 5 fev.

23. Kapp KM. The Gamification of learning and instruction: Game-based methods and strategies for training and education. San Francisco: Pfeiffer; 2012.

24. Casagrande ACGH. Mead \& a Educação. Belo Horizonte: Autêntica Editora; 2014.

25. Aldamiz-Echevarria C, Aguirre-Garcia MSA. Behavior model for blood donors and marketing strategies to retain and attract them. Rev. Latino-Am. Enfermagem 2014; 22(3):467-475.

26. Kotler P, Kartajaya H, Setiawan I. Marketing 4.0 - do tradicional ao digital. Rio de Janeiro: Sextante; 2017.

27. Bruhin A, Goette L, Haenni S, Jiang L. Spillovers of Prosocial Motivation: Evidence from an Intervention Study on Blood Donors. J Health Economics 2020; 70.

28. Alexandre NMC, Coluci MZO. Validade de conteúdo nos processos de construção e adaptação de instrumentos de medidas. Cien Saude Colet 2011; 16(7):3061-3068.

Artigo apresentado em 11/03/2020

Aprovado em 22/04/2020

Versão final apresentada em 24/04/2020

Editores chefes: Maria Cecília de Souza Minayo, Romeu Gomes, Antônio Augusto Moura da Silva 
